\title{
Translation and Interpreting as a Profession: Some Proposals to Boost Entrepreneurial Competence
}

\begin{abstract}
Increasing automation and the emergence of new needs and forms of communication are triggering a redefinition of the role and work settings of translators and interpreters. For this reason, and with a view to enhancing employability, students need to be aware of the range of professional profiles they can pursue and the value they can bring to society. The aim of this paper is to put forward a series of teaching proposals aimed at promoting entrepreneurial competence. After presenting the results of an exploratory study of students' views of the profession, it proposes some activities that are considered particularly useful for fostering entrepreneurial competences.
\end{abstract}

\section{Keywords}

employability; entrepreneurial competence; versatility; teaching proposal; exploratory study

\section{Introduction}

Changes are currently taking place in translation and communication needs. These changes, prompted by increasing internationalisation of business, generation of new forms of communication in ever-increasing digital environments, and especially the advance of new technologies, are modifying the role of translators and interpreters and the work settings in which they practise their profession. In an era of growing automation, in which the very survival of translation as a long-term human activity is being questioned (Calvo 2017), it is therefore necessary to explore new professional paths and ways of finding employment in which the human factor is not only desirable but of critical importance.

This situation has an impact on training, since it may involve, on the one hand, redefining and even extending the range of tasks and roles expected of translators and interpreters (Angelone 2018, Massey/Wieder 2018) and on the other, enabling students to find market niches to which they can respond, that is, encouraging the acquisition of entrepreneurial skills and training for employability (Galán-Mañas 2018).

Although specialisation has traditionally been considered one of the most effective ways to enhance employability (Henter 2016, Álvarez-Álvarez/Arnáiz-Uzquiza 2017), more and more authors argue instead for promoting generic and transversal competences (Pym 2005, Kelly 2007, Morón/Medina 2016, Calvo 2017, Morón 2017, Rodríguez 2017) to foster students' versatility (Morón 2012, Muñoz-Miquel et al. 2017) and ability to adopt new perspectives (Montalt 2011) in response to changing market needs. In this regard, students are also expected to be aware of the range of professional profiles they can pursue thanks to the competences acquired during the Bachelor's Degree in Translation and Interpreting (TI), and to be able to "generate new work settings in response to emerging social needs" (Calvo 2017: 152, my translation) in which their skills represent an added value (Morón 2017).

\footnotetext{
* Ana Muñoz-Miquel

Departamento de Traducción y Comunicación

Universitat Jaume I

E-mail:munoza@uji.es
} 
This paper starts from a holistic (Dam et al. 2018) and transversal (Morón 2017) view of TI as a profession and bases on the notion of entrepreneurship (Marina 2010) with the object of presenting a series of didactic proposals aimed at fostering entrepreneurial competence with a view to enhancing employability. To this end it discusses some of the activities implemented in a course unit on professional issues, The Professions of the Translator, introduced in the Bachelor's Degree in Translation and Interlinguistic Mediation at the Universitat de València in the academic year 2016/2017.

The paper is structured as follows: Section 2 discusses the notions of employability and entrepreneurial competence; Section 3 deals with entrepreneurial competence and versatility from the Translation Studies' perspective; Section 4 presents the results of an exploratory study of students' views of the profession; Section 5 proposes some activities that are considered particularly useful for fostering entrepreneurial competences; and Section 6 presents some concluding remarks.

\section{Employability and entrepreneurial competence}

In recent years there has been an increasing interest in bridging the gap between university education and professional practice by promoting employability, defined as "the ability to gain initial meaningful employment, or to become self-employed, to maintain employment and to be able to move around the labour market" (Working Group on Employability 2009: 5). Although, as Rodríguez (2017: 108) points out, the notion of employability is very frequently interchangeable with that of employment, they refer to different concepts. Whereas "employment can be measured and quantified to some extent, [...] employability entails a series of skills that go beyond the aim of becoming part of the labour market" (Rodríguez 2017: 108). Employability therefore has to be seen "as a holistic process and not simplistically as a record of employment" (Rodríguez 2017: 109).

Those overseeing the current process of consolidating the European Higher Education Area (EHEA) have underlined the need to continue working to ensure that graduates "possess competences suitable for entry into the labour market which also enable them to develop the new competences they may need for their employability later [...]" (European Ministers Responsible for Higher Education 2015: 2). This perspective requires adopting models that combine retrospective training (anchored in pre-existing profiles) with a more transformative and prospective kind of training (Calvo 2017: 143) that helps to identify potential opportunities for entering the everchanging market and emphasises the skills needed to adapt to it. As Chouc/Calvo (2010: 72) put it:

\footnotetext{
[E]mployability is not only about responding to short-term market needs (a quantitative perspective based on the specialised profiles most in demand at a given time), but rather about generating competent, active social agents that are able to react to any given context (qualitative view).
}

The concept of employability is closely related to that of entrepreneurship or entrepreneurial competence. Entrepreneurship, originally part of general business and economic studies, is usually associated with issues strictly related to establishing new enterprises, revitalising existing companies and stimulating the entrepreneurial mindset required for progress (Duarte 2007: 46). For this reason, entrepreneurship training has traditionally been offered in business schools (European Commission 2008: 7). However, from an educational perspective, entrepreneurial skills are not just about boosting start-ups, innovative ventures and new jobs (European Commission 2008: 12 ), but have to do with initiative and versatility in a very broad sense. This is why current European employability policies call for their inclusion in non-business studies, including humanities (European Commission 2008: 12). But what exactly does entrepreneurial competence mean and what does it involve?

There is no consensus on what to call it; the EU's Entrepreneurship Competence Framework or the Organisation for Economic Co-operation and Development to mention a few examples, refer to "acting autonomously", "entrepreneurial spirit", "autonomy and personal initiative" (Marina 
2010: 55, my translation). Despite this heterogeneity, all these terms refer to a set of skills, attitudes, values and knowledge that could be grouped into four main areas:

\begin{tabular}{|c|c|}
\hline $\begin{array}{c}\text { Area of } \\
\text { entrepreneurial } \\
\text { competence }\end{array}$ & Description \\
\hline $\begin{array}{l}\text { Initiative } \\
\text { and strategic vision }\end{array}$ & $\begin{array}{l}\text { - Identifying one's own strengths and weaknesses, as well as } \\
\text { one's own interests and those of others. } \\
\text { - Identifying areas where one's own skills can be demonstrated } \\
\text { and add value. } \\
\text { - Building arguments with which to defend a position, and } \\
\text { - Haggesting agreements and solutions. } \\
\text { - Showing a strategic vision of challenges and opportunities. }\end{array}$ \\
\hline $\begin{array}{l}\text { Adaptability } \\
\text { and versatility }\end{array}$ & $\begin{array}{l}\text { - Showing a positive attitude towards change and innovation. } \\
\text { - Accepting changes brought about by external factors, adapting } \\
\text { critically to them and seeing them as opportunities. } \\
\text { - Turning ideas into actions, rethinking previous perspectives, } \\
\text { looking for solutions and putting them into practice. } \\
\text { - Developing one's potential. }\end{array}$ \\
\hline $\begin{array}{l}\text { Project planning } \\
\text { and development }\end{array}$ & $\begin{array}{l}\text { - Carrying out the necessary actions to develop professional and } \\
\text { personal projects: defining and planning, analysing possibilities } \\
\text { and limitations, identifying and evaluating resources, } \\
\text { establishing priorities, making decisions, organising times and } \\
\text { tasks, monitoring progress, drawing conclusions, assessing } \\
\text { possibilities for improvement, communicating results. } \\
\text { - Getting to know the rules and principles of a given context or } \\
\text { situation (e.g., professional and labour market issues). } \\
\text { - Self-confidence, leadership and capacity for self-evaluation and } \\
\text { improvement. }\end{array}$ \\
\hline $\begin{array}{l}\text { Cooperation } \\
\text { and teamwork }\end{array}$ & $\begin{array}{l}\text { - Working cooperatively and with flexibility as part of a team. } \\
\text { - Empathy, capacity for dialogue and negotiation, responsibility, } \\
\text { critical thinking, assertiveness and flexibility. }\end{array}$ \\
\hline
\end{tabular}

Table 1. Description of entrepreneurial competence (adapted from Marina 2010: 56 ff.)

As we can see, getting to know the labour market, being aware of one's own abilities, knowing how to take advantage of opportunities, create a demand for one's services and provide added value, being versatile and having initiative are some of the essential aspects of entrepreneurial competence. For this reason, and in line with what Galán-Mañas (2018: 50) suggests, entrepreneurial competence not only contributes to business start-up and self-employment; by fostering the development of the transversal skills, adaptation to a changing market and even management of both "personal and professional life" (Galán-Mañas 2018: 50) are facilitated. 


\section{Entrepreneurial competence and versatility in TI}

In the field of Translation Studies, most translation competence (TC) models that have been applied to translator training do not explicitly refer to entrepreneurial competence. By way of example, the TC model proposed by Kelly $(2002,2007)$, which has significantly influenced curriculum design, includes the following sub-competences:

\footnotetext{
Communicative and textual competence: comprehension and production of texts, knowledge of the main textual genres, etc.

Cultural competence: knowledge of values, beliefs, institutions, etc.

Subject area competence: a basic grasp of the subject areas to be translated. Professional and instrumental competence: knowledge of the profession and the market, identification
and evaluation of documentary resources, use of ICT tools, etc.

Psychophysiological and attitudinal competence: professional self-awareness, confidence, autonomy, creativity, etc.
}

Interpersonal competence: teamwork, justifying decisions, communication skills, etc.

Strategic competence: identifying and solving problems, self-evaluation, etc.

In this proposal and in others (see PACTE 2003 or Hurtado Albir 2007), we can see some convergences with entrepreneurial competence in the professional, psychophysiological/attitudinal, interpersonal and strategic sub-competences. However, these are limited, since they do not include most of the issues identified in Table 1.

Despite the fact that entrepreneurial competence as such does not seem to have a space 'of its own' in the main TC models, an increasing number of studies address employability with a view to fostering entrepreneurship among students (Vandepitte 2009, Calvo et al. 2010, Chouc/Calvo 2010, Thelen 2016, Way 2016, Calvo 2017, Rodríguez 2017, Galán-Mañas 2017, 2018). These works refer mainly to initiatives of a curricular or extracurricular nature, such as internships, real translation assignments and professional tasks, seminars by professionals and career fairs. In this regard, Galán-Mañas (2018) offers a comprehensive list of tasks for students, from writing a cover letter to formulating business and marketing plans.

Another measure often mentioned is to include course units on professional issues in TI curricula. Although this initiative would help students acquire a wide range of entrepreneurial and profession-related skills, the data shown in Álvarez-Álvarez/Arnáiz-Uzquiza (2017) are discouraging. They analysed the 33 TI bachelor's degree programmes in Spain and concluded that only 9 offer a course unit on professional issues. A more detailed analysis of their syllabuses shows that they are very heterogeneous and that although most of them deal with matters directly related to the profession (procedure for registering as self-employed, tax, professional ethics, etc.), three of the nine focus exclusively on how to set up a business. At a master's level we find more optimistic results. Based on the European Masters in Translation (EMT) guidelines, which confer a central role to professional competences, Torres-Simón/Pym (2017) analysed the master's degree programmes that belonged to the EMT network at that time and concluded that 44 out of the 66 offered courses on the translation profession or related and that these courses made up from 2 to 17 percent of the total credits of the programmes.

Although the contents taught in all these courses are of paramount importance, they may not be enough to develop certain aspects of entrepreneurial competence (initiative, searching for career opportunities, creating a demand, adapting to change) that are key to promoting employability in an era of increasing automation and change in which, as noted in Section 1, a redefinition and extension of the tasks traditionally associated with TI may be required. 
To this end, students should be made aware of the potential and versatility of TI as a degree and as a career. Considering the clear commonalities between the sub-competences of TC and those regarded as generic or transversal within the EHEA framework (González/Wagenaar 2003: 83$84)$, there is no doubt that TI is a very versatile discipline that offers graduates a flexible training. As Kelly points out (2007: 135):

\begin{abstract}
[...] as a discipline, translation offers access to a very wide range of competences [...]. Thus, if we take the list of generic competences drawn up as a basis for the work of the Tuning project [...], and compare it with the summary-catalogue of translator [...] competences offered above, graduates from translator training programmes appear almost uniquely qualified as flexible, adaptable and highly employable citizens.
\end{abstract}

In line with this view, with reference to Spain, an increasing number of authors criticise the excessive rigidity of the profiles proposed in the White Paper on the TI Degree ${ }^{1}$ and advocate fostering transversal competences to be able to respond to emerging and diverse professional tasks (Pym 2005, Kelly 2007, Morón/Medina 2016, Calvo 2017, Rodríguez 2017).

Although authors such as Mossop (2016) argue in favour of limiting the scope of TI to equifunctional translation between different languages, recent empirical studies with professional translators and/or employers (Toudic 2012, Muñoz-Miquel 2016, 2018, Rico/García 2016, Brøgger 2017, Galán-Mañas 2018) show that professionals perform a variety of tasks beyond what has traditionally been considered translation proper (Jakobson 1959/2000: 114) and work in varied sectors and contexts (Chouc/Calvo 2010). These professional tasks include: intralingual or expert-layman translation (Zethsen 2018), genre shifts addressed to the same type of audience (e.g., turning research articles into conference presentations), editing, pre- and post-editing for machine translation, multilingual content management of websites and social media, adapting texts to a 'neutral' variety of Spanish, linguistic and cultural consultancy, localisation, desktop publishing and website design, transcription, project management, audio description, subtitling, dubbing, corporate communication, interpreting, mediation in public services, voice-over, proofreading in all its forms, back-translation, writing original texts, summary translation, creating terminology databases, etc. The sectors in which these tasks may be required are also diverse: language and communication services, international trade, tourism, event management, secretarial work, multilingual marketing, logistics, education, research, etc.

As we can see, in addition to 'traditional' translation and interpreting tasks there is a wide range of job opportunities that "go beyond the traditional alternative as a language-teaching professional" (Calvo et al. 2010: 214). The question, then, is whether students are aware of the versatility of TI and of how they can take advantage of it to enhance their employability.

\title{
4. Exploratory study of students' perception of the profession
}

Starting from the premise that TI students may not be fully aware of the versatility of the discipline, and given the limited and disparate training they receive in entrepreneurship and professional issues (Álvarez-Álvarez/Arnáiz-Uzquiza 2017), we carried out an exploratory study in which first-year and final-year students participated. The objectives were 1) to find out how students perceive TI as a career and the professional activities available and 2) to determine whether there are differences between the perceptions of first-year and fourth-year students.

\subsection{Method}

The study included 67 first-year students enrolled on the Bachelor' Degree in Translation and Interpreting at the Universitat Jaume I, Spain, and 74 fourth-year students, of whom 36 were taking

1 The White Paper on the TI Degree is a report which was drawn up by a network of Spanish Higher Education Institutions and the ANECA (Spanish National Agency for Quality Assessment and Accreditation) to assist the design and implementation of bachelor's degrees according to the EHEA requirements. See: http://www.aneca.es/var/media/150288/libroblanco_traduc_def.pdf. Accessed 20 February 2020. 
the aforementioned degree and 38 the Bachelor's Degree in Translation and Interlinguistic Mediation at Universitat de València, Spain. All the fourth-year students, despite studying at different universities, had similar profiles: all of them had already done internships or were doing them at that time, and none had taken any course on professional issues or entrepreneurship.

The questionnaire (see Appendix 1) consisted of four ${ }^{2}$ open questions and covered the following: 1) the students' knowledge of the degree before enrolling on it, 2) the reasons why they decided to study TI, and 3) the career opportunities they consider TI offers and the professional tasks they think a TI graduate could perform. We used open questions to avoid influencing the responses.

We used either a paper format or a GoogleForms questionnaire, depending on the course. The answers were collected at different times, though all in 2017. Although the data were qualitative, they were analysed both qualitatively and quantitatively: we first analysed the responses and classified them in categories (types of reasons to enrol on TI degree, types of tasks identified, etc.), to find points of convergence. Then we quantified their frequency to facilitate the comparison between first-year and fourth-year students. The result of this quantitative analysis, which was performed with Microsoft Office Excel, is shown in Figures 1 to 6 (see Section 4.2).

Although the study has important limitations (it was not longitudinal and the sample was small), it provided a general impression of the students' perceptions.

\subsection{Results}

First, we present the data obtained in the questionnaires addressed to first-year and fourth-year students, and then we compare and discuss the results.

\subsubsection{First-year students}

As one can see in Figure 1, the majority said they were well aware of the degree before enrolling, and the remaining stated that they had no knowledge of it or 'only a little'.

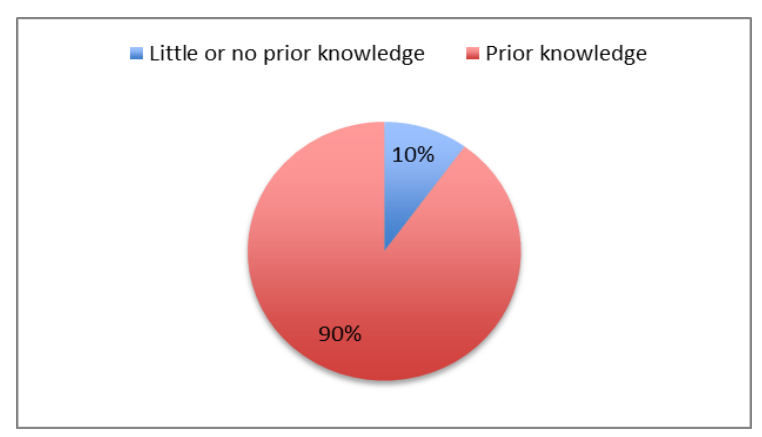

Figure 1. Prior knowledge of the degree (first-year students).

Regarding the reasons to enrol on this degree (Figure 2), the overwhelming majority (97\%) referred to a love of languages, which they also associated with opportunities to learn 'many' languages. Twelve per cent stated that they loved travelling. Among the least frequently mentioned reasons we find a 'vocation for being an interpreter' or an 'opportunity to work in publishing houses'.

2 The questionnaire addressed to fourth-year students included one more question about future job expectations (see Appendix 1) that was not analysed in this paper. 


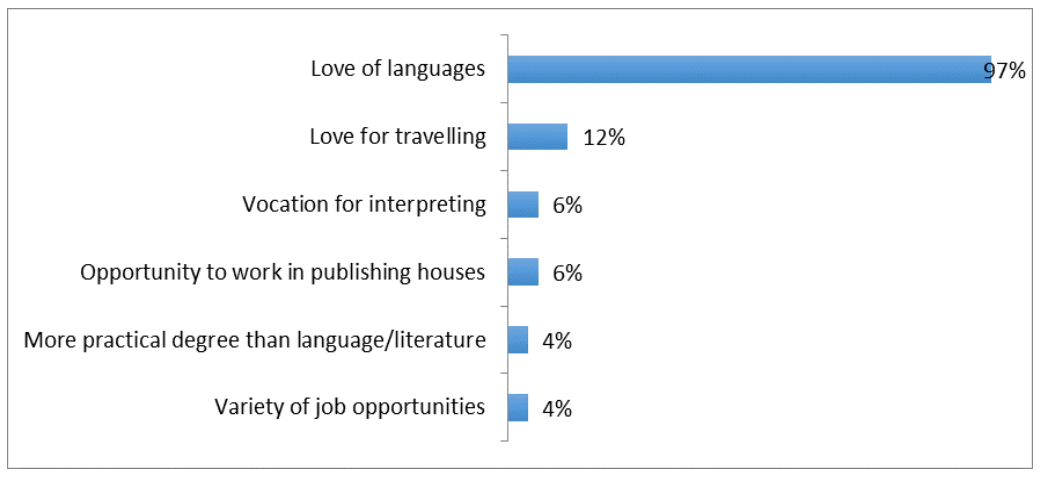

Figure 2. Reasons to enrol on TI (first-year students).

Concerning career opportunities, Figure 3 shows that the most striking point is that the range of activities identified was almost entirely uniform. The most frequent responses were translation, interpreting and teaching. Twenty-three per cent mentioned mediation and $13 \%$ proofreading/editing, although the responses show that these concepts are unclear for many of them. 'Linguist' was also mentioned as a possible career option. Other career opportunities mentioned once were 'tourist guide', 'working in a factory talking to suppliers from other countries', 'book publisher', 'explaining a text' and 'spokesperson in organisations'.

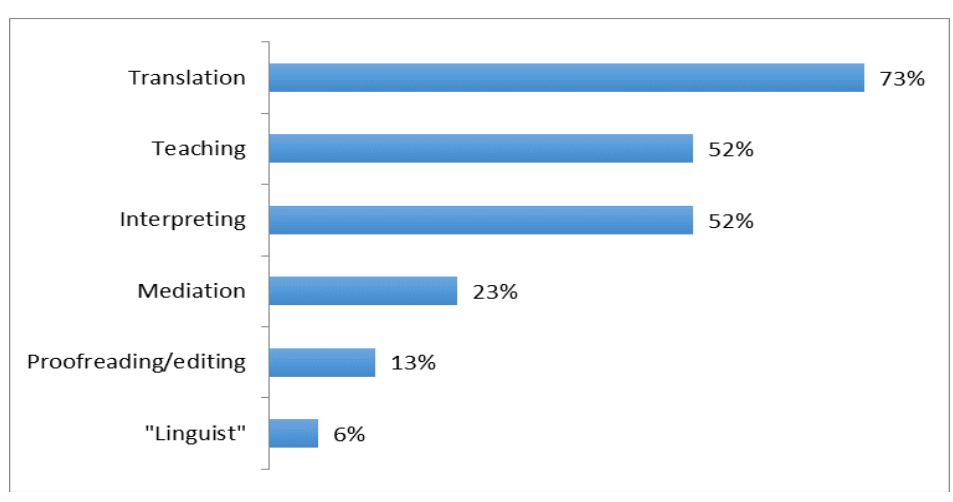

Figure 3. Professional tasks and job opportunities identified (first-year students).

From a qualitative point of view, the results show that although the majority do know the difference between translation and interpreting, this is not always the case, as we find responses such as 'translating in conferences', 'written translation of any type of text', 'simultaneous oral and written translation' or 'translator of conversations'.

It is also notable that in relation to translation as a professional activity the most widespread tendency was to refer, albeit indirectly, to the publishing sector, in that expressions like 'book translator' were mentioned by many respondents. Interpreting, however, is mostly associated with international organisations; the most common response was 'interpreter at the UN' or something similar.

The students' unfamiliarity with the metalanguage of the TI field was also evident. Frequent examples in responses were 'dubber', 'translator of films' or 'individual translator'. 


\subsubsection{Fourth-year students}

Fifty-six per cent reported that they had had little or no knowledge of the TI degree before enrolling, and the remaining stated that they had been well aware of it (Figure 4). It is striking to find statements like 'I thought I did, but I realised there were many things I didn't know'.

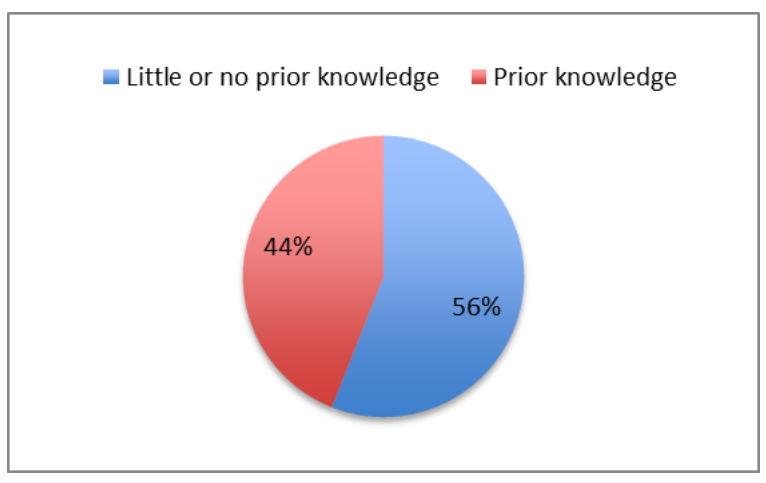

Figure 4. Prior knowledge of the degree (fourth-year students).

Regarding the reasons to enrol on TI, Figure 5 shows a variety of responses, although a love of languages still predominates (74\%), well ahead of reasons such as TI being a more practical degree than language and literature (15\%) or having a genuine interest in translation $(12 \%)$.

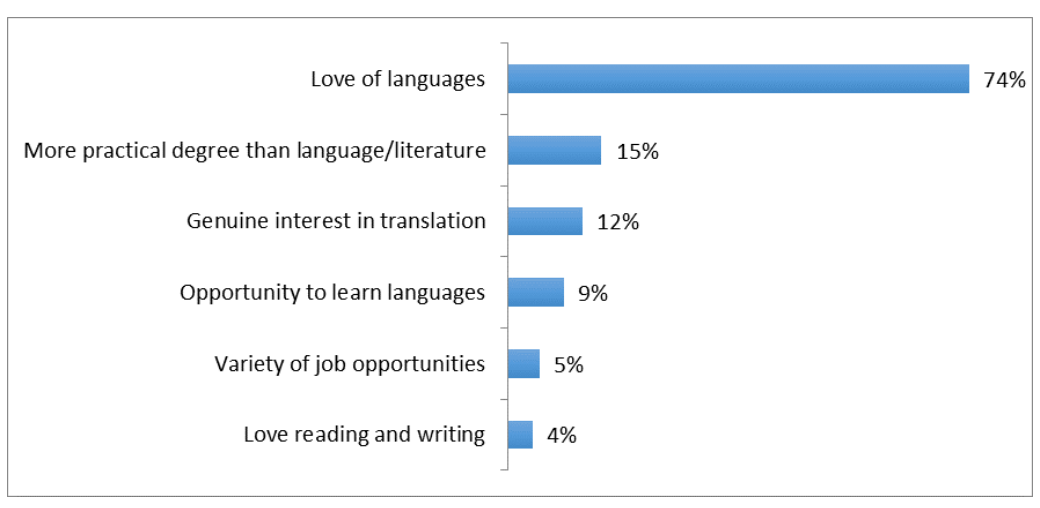

Figure 5. Reasons to enrol on TI (fourth-year students).

As for the professional tasks (Figure 6), the most traditional options predominate, coinciding with the first-year students' responses: translation, teaching, interpreting and proofreading. These are followed by revision, editing, project management, mediation, and other tasks traditionally associated to the profession. Nine per cent referred to different possible modes of employment (selfemployed or in-house). The following job opportunities were mentioned once: layout editor, transcriber, language adviser and tourist guide. 


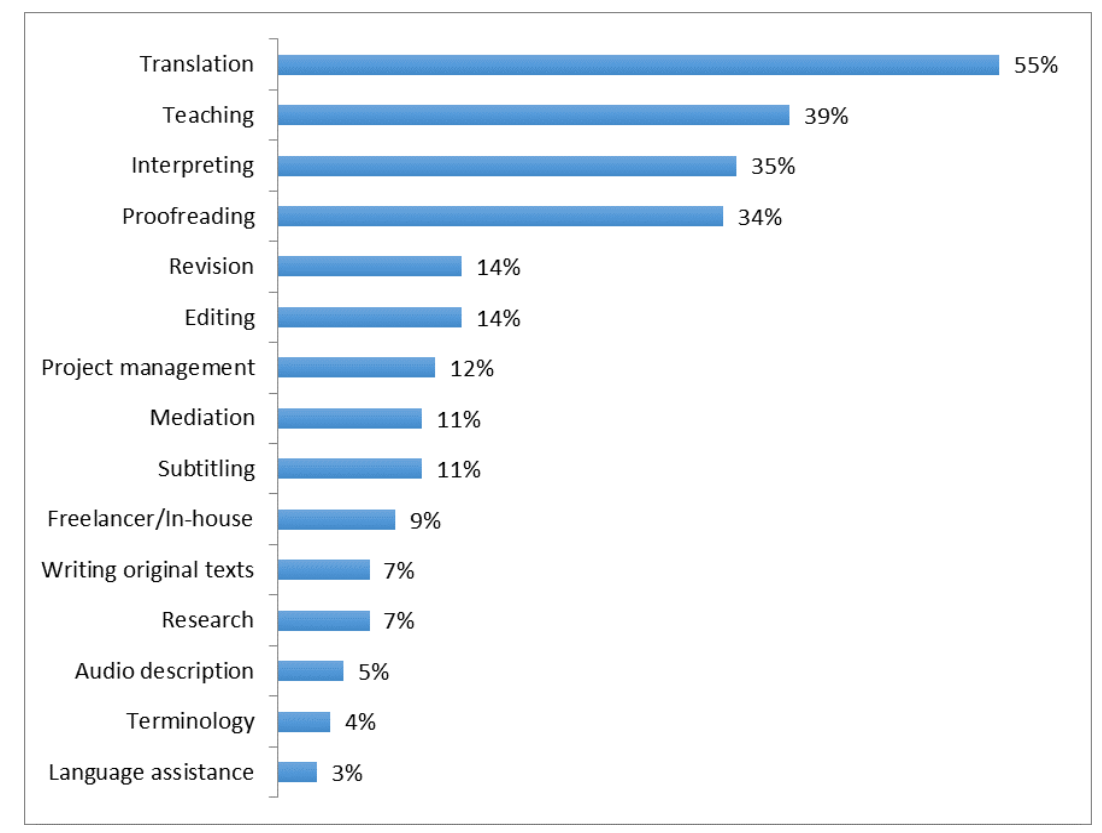

Figure 6. Professional tasks and job opportunities identified (fourth-year students).

It is striking to find a large number of vague responses, such as 'translating texts or mediating between people', 'helping people to communicate', 'mediating between cultures' or 'intercultural professions', which would be more typical of students not yet familiar with the discipline.

\subsubsection{Comparison and general impressions}

Although the students are not from the same cohort, the results show changes in their opinions. The first is that the degree seems to have become demystified when they reach the final year. While nearly all the first-year students considered that they had sufficient prior knowledge of the TI degree, the percentage of students who think so drops considerably by the fourth year. This could suggest that once they reach the last stage of their degree, they realise that it has not met their initial expectations, which does not necessarily mean that they have a negative opinion of it. In addition, the view of the profession as an opportunity to travel, learn many languages or occupy socially prestigious positions, such as being a UN interpreter or a translator for a publishing house, evolves and becomes more realistic as one reaches the final year. The range of professional activities that are identified is extended and the metalanguage used to refer to profession-related issues improves. However, the professional tasks most often mentioned by both cohorts are virtually the same and match those traditionally associated with this career: translation and interpreting, teaching and proofreading.

While other profession-related activities such as revision, editing, writing or project management are mentioned by final-year students, the percentage is quite low. It is striking, then, that they are not aware of other kinds of work, associated with new technologies and communication needs, for which their training could suit them. The results therefore suggest that becoming aware of the competences they have acquired and enhancing their potential are matters still requiring attention for these students.

\section{Teaching proposals aimed at fostering entrepreneurial competence}

As already mentioned, the activities proposed here were implemented in a course unit on professional issues. In designing them, we took into account the results obtained in the questionnaires and 
adopted a holistic view of TI as a profession (Dam et al. 2018) capable of fostering the emergence of new professional profiles in response to social and market needs (Kiraly 2016).

\subsection{Characteristics of the course unit}

The Professions of the Translator is an elective course introduced at Universitat de València in the academic year 2016/17. It is worth 6 ECTS credits (150 working hours, of which 60 are contact hours) and is taught in two weekly sessions of two hours during the second semester of the final year of the bachelor's degree programme. The total number of sessions is 30 .

The main objective is for students to get to know some professional facets of TI as a career and acquire skills related to entrepreneurial competence. The teaching units are as follows:

1. The profession of the translator and interpreter.

2. Specialities, clients and modes of employment or self-employment.

3. Profiles and professional activities.

4. Promoting one's services and finding clients.

5. Tax issues and professional management for self-employed translators.

6. Professional associations and ethical issues.

With regard to methodology, theoretical and practical lessons, readings and debates are combined with individual and team work. Some collaborative activities are also conducted through the virtual classroom, which is based on the Moodle platform.

As for assessment, students deliver exercises on specific topics throughout the semester; these represent $40 \%$ of the final mark. The remaining $60 \%$ is awarded for two final assignments, one individual and the other in groups, putting all the competences acquired during the semester into practice.

\subsection{Proposed activities}

Among the activities of this course unit, we have selected those that in our judgement best enhance entrepreneurial competence, with special emphasis on initiative, versatility, promoting one's services and finding job opportunities.

The proposed activities - taught in units 1,2,3 and 4 - are presented sequentially and cover, broadly speaking, different phases of entrepreneurship, from getting to know the market and the profession to being able to draw up a plan for entering the labour market. These activities are as follows:
1. Continuous assessment activities:
2. Wiki on professional issues.
3. Beyond translation proper.
4. The linguist as an activist.
5. CV and cover letter.

Final activities for incorporating competences:
1. Professional website.
2. Personal route-map. 
The details are explained in the following sections: description of the activity and objectives, areas of entrepreneurial competence (as seen in Table 1) to be acquired, and assessment method. In addition, the particular sub-competences of TC that are put into practice are specified.

\subsubsection{Wiki on professional issues}

The objective of this wiki-based activity, which was introduced in the second session of the course and lasted until the end of the semester, was to create a collaborative repository of useful information for acquiring in-depth knowledge of the profession.

Students were required to create contents according to a specific template with items of various kinds: translation agencies; non-translation-related companies that might require translation/ interpreting services; organisations with TI services; job offers; associations; professional websites; TI-related blogs, forums, lists and social media accounts; journal articles related to professional issues, etc. They were told that they could not contribute a resource that a fellow-student had added already, although they could expand on or improve the information already published.

Students were expected to familiarise themselves with the TI market and with finding potential clients, issues corresponding to the project planning and development area of entrepreneurial competence. With regard to TC, the sub-competences students worked on were the professional, communicative and textual, and instrumental: they had to get to know the market, make sure that the content was well written before publishing it, and contribute new resources that matched the given categories.

As for assessment, during the semester each student had to make a minimum of four contributions, which were assessed for their relevance and clarity.

\subsubsection{Beyond translation proper}

This title does not refer to a specific activity but to a series of tasks carried out during the first three teaching units. Our aim was to encourage students to reflect on: what TI is and what it involves, what activities they could perform, what they could contribute to society and what market niches they could occupy in the medium term. We also addressed TI specialities and modalities, and the students' preferences for some over others, according to their own skills and interests.

The tasks carried out included the following:

Debates revolving around articles on the identity of translators and the status of the profession; e.g., ,I think It Is a Wonderful Job': On the Solidity of the Translation Profession (http://www.jostrans.org/ issue25/art_dam.php); The Status of the Translation Profession in the European Union: (http://www. termcoord.eu/wp-content/uploads/2013/08/The_status_of_the_translation_profession_in_the_European_Union.pdf).

Identifying and characterising textual genres from various specialities: main features, contexts in which they might need to be translated, competences required, difficulties involved, etc.

Readings and practical exercises on work processes: how to set up as a freelancer, how to find clients, what to look for when identifying companies in which the skills of a translator/interpreter would provide added value, etc.

Readings and practical exercises to explore a varied range of professional tasks: proofreading, revision, project management, expert-to-layman adaptation, multilingual communication management, post-editing, teaching, research, etc.

Depending on the type of activity, students were required to work individually or in pairs.

The main area of entrepreneurial competence to be developed was project planning and development (to deepen their knowledge of the profession and the market). However, we also wanted to boost their initiative and strategic vision (identifying their own strengths, weaknesses and interests) and their adaptability and versatility (understanding that the ever-changing market forces 
us to be constantly redefining the communication needs to which translators/interpreters can respond).

While conducting these activities in class, we realised that the students knew very little about these professional issues, which is consistent with the results obtained in the questionnaires (see Section 4).

\title{
5.2.3. The linguist as an activist
}

This activity of unit 4 is based on an article by Xosé Castro, a professional translator, with precisely this title: The Linguist as an Activist (El lingüista como activista: https://cvc.cervantes.es/trujaman/anteriores/septiembre_01/26092001.htm). This article addresses the importance of demanding that texts in one's mother tongue should be well-written, and of adopting a proactive attitude towards those that are not. As Castro points out (2001: online, my translation):

\begin{abstract}
If we do not demand good translation and good writing in our own language, we cannot complain about bad translations and texts being commissioned and approved. [...] I sent [a dubbing director] an eight-page fax rationally and respectfully pointing out $[\ldots]$ the monumental solecisms and linguistic outrages in one of her films [...].
\end{abstract}

The article, which we consider a salutary lesson for developing one's initiative, was used to perform two tasks.

First we created a forum in the virtual classroom for the students to comment on any mistranslation or bad writing they found and the reason why it was incorrect or needed to be improved. To start the discussion, we used a striking translation error we found on the university's website as an example. During the semester the students posted more than thirty examples of every kind: emails from online sales companies, textbooks, newspaper articles, notices, advertisements, etc.

In the second task we asked students to select one of the examples shared in the forum and write a letter to those in charge of the company or organisation in question. In this letter they had to explain the errors and deficiencies "rationally and respectfully" (Castro 2001: online, my translation) and suggest how they could contribute to improving the situation. They therefore had to take the opportunity to promote their skills as experts in communication, language and culture. The letter had to be actually sent. ${ }^{3}$

The areas of entrepreneurial competence to be acquire were initiative and strategic vision (valuing one's own skills, showing initiative, creating a demand) and adaptability and versatility (turning ideas - complaints in this case - into actions and offering solutions). As this activity was done in pairs, fostering the ability to cooperate was also key.

As regards TC, the sub-competences involved were communicative and textual (knowledge of the characteristics of the letter genre, ability to detect and correct errors), instrumental (through the searches that may be required to identify who the letter should be addressed to in order to be effective) and strategic (identifying and solving problems).

To assess the activity, in addition to correcting every letter individually, we read several of them in class and commented on their suitability from various perspectives: whether they were convincing or might provoke a hostile reaction, whether they were well written and followed the conventions of this genre, etc. For this purpose we asked our students to adopt the role of the addressee.

The students found this task very useful, though quite demanding, as it was very difficult for them to provide effective yet respectful arguments and to suggest solutions that would enable them to promote and raise awareness of the value of their work.

3 Two students received a response from a well-known airline company, which thanked them and undertook to correct the mistakes. 


\subsubsection{CV and cover letter}

This activity is similar to the previous one, although with some features that make it relevant.

Using the information on companies that they had compiled in the wiki, we asked the students to choose two of them: one had to be a translation agency and the other a company that was not directly related to translation but in which language or communication professionals might be required. They had to draw up a CV and a cover letter adapted to each case. As a preliminary step, we provided them with resources on how to prepare a CV and a cover letter, and we worked on these genres by providing them with real examples of varying quality. We also addressed the importance of building one's own brand image.

We aimed to work on the same areas of entrepreneurial competence and sub-competences of $\mathrm{TC}$ as in the previous task, but in a different way, since this activity was individual. Evaluation of one's own skills, self-promotion and adaptation to the distinctive features of different customers were crucial.

We should note that although writing a letter to a translation agency was relatively easy for them, it was difficult to engage their creativity and get them to write it without using too many conventional expressions. As for the letter addressed to a non-translation-related company, what they found most difficult was identifying work opportunities, highlighting their skills without resorting to clichés, and making potential clients aware of their value.

Preparing their CV was also a demanding task because they had to stick to the reality of their situation at that time and not to simulate hypothetical academic qualifications or work experience. Writing a 'real' CV with little information to provide made them feel hesitant and insecure. However, discussion and reflection in class played a key part in enabling them to complete the activity successfully.

To assess these tasks we provided personalised correction of their work, and as in the previous activity we discussed various proposals in class and the students adopted the roles of different employers. Despite the difficulties, they found these tasks very challenging and useful.

\subsubsection{Professional website}

Our students had to create a professional website in groups of three using free website builders, such as Wix, Weebly, etc. In doing so, they had to take account of the explanations given in class about marketing for translators and use other professional translators' websites as references. They were free to decide how to structure their website and what services to offer. Although these guidelines were provided in unit 4, students worked on this project until the end of the course.

This activity served to put into practice the knowledge and skills they had been acquiring during the semester (professional services and tasks, promotion and brand image, estimates and pricing, etc.) in a simulated way, but coinciding as closely as possible with their interests. In this way we aimed to reinforce their entrepreneurial competence as a whole, with emphasis on cooperation and teamwork, and many sub-competences of TC: communicative and textual (writing in their mother tongue, knowledge of the professional website genre), instrumental (familiarising themselves with website creation programs), professional (knowledge of pricing), strategic (organisation and revision) and psychophysiological (creativity).

To enable us to assess their work, the students had to write a report giving the URL of their website and explaining how they had developed it and which criteria had applied.

We were pleasantly surprised by the creativity shown by most groups, who found this experience useful and motivating, as it enabled them to put themselves in the shoes of real professionals. 


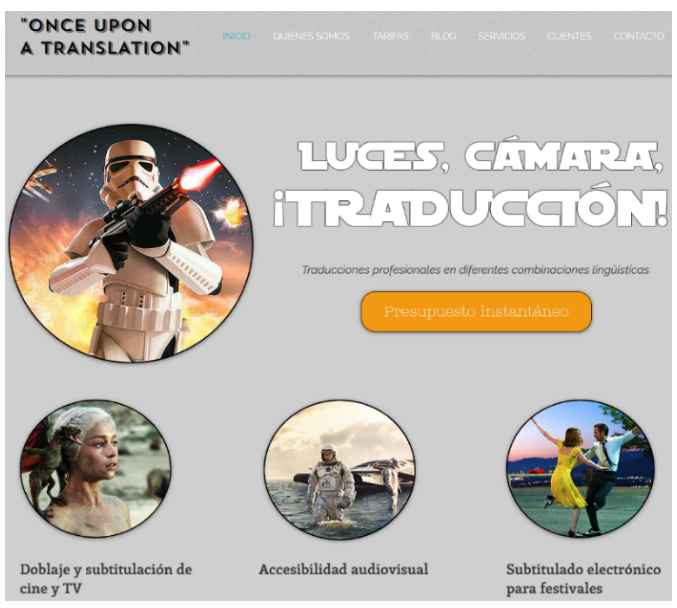

Figure 7. The home page of one of the websites created by the students.

\subsubsection{Personal route-map}

In response to the question 'I'm about to finish my degree, what now?', students had to draw up a route-map in which they explained and reflected on the steps they wanted to take once they had graduated. They had to apply what they had learned to their own real situation.

Given the reflective and personal nature of the task, this route-map is similar to what is known as a portfolio (Galán-Mañas/Hurtado Albir 2015: 72, Calvo 2017: 146), but with the special feature that it had to conform as closely as possible to their real situation in the short to medium term. The students were therefore not expected to simulate a hypothetical situation but to develop reasoned thoughts that reflected their interests and highlighted their skills.

Although they were given complete freedom to structure their work, we posed some questions to guide their reflections: What does TI mean to me? What difference has doing this degree made to me? Bearing in mind my qualities and interests, what professional activities would I like to perform? Which sectors and specialities would I be particularly interested in? Would I prefer to be employed or self-employed? How would I start my professional career? What strategies would I use to find clients? Would I like to combine translation with another job? How would I search for that job? How would I manage my career? ${ }^{4}$ Would I become a member of any professional association? Would I follow any code of practice? ${ }^{5}$ Would I need to continue my training? On what, where and why?

Work opportunities had to be related to the competences acquired during the TI degree, but there was no obligation to follow the most traditional option, that is, working as a freelance translator, if this was not what they wanted to do. Their route-map had to be as real as possible to achieve the aim of the activity: to confront the feeling of emptiness that students experience when they finish their degree and to design their personal entrepreneurial strategy.

In addition to their thoughts, students had to include examples illustrating the strategies they would use to start their career and look for clients: e.g., a letter and CV addressed to a specific company, a list of potential clients to send their $\mathrm{CV}$ to, a sample of their professional services, etc.

The students were expected to put into practice their entrepreneurial competence as a whole except for teamwork, and a range of sub-competences of TC which had already been worked on

4 In unit 5 we worked on various aspects of tax and career management: procedures for registering as self-employed, preparing estimates and invoices, managing client complaints, setting prices, etc.

5 In unit 6 we addressed everything to do with professional ethics and association membership. 
in previous activities: communicative and textual, professional, instrumental, psychophysiological and strategic.

The assessment was based on their originality and their ability to apply what they had learned in the course to their particular case and structure their ideas coherently. Mere repetition of the contents dealt with in class received a negative assessment.

The results were very encouraging. The students considered a wide range of possibilities: spending a year working abroad as a Spanish teacher and then looking for a job as a staff translator; setting up a language services company; doing a master's degree in international trade and looking for a job in that sector; setting up as a freelancer and taking some specialisation courses; etc.

\subsubsection{Extracurricular activities}

Three talks were given by practitioners in the field. The speakers, who had graduated within the last five years and had pursued different career paths, explained their professional experience and gave our students useful tips. They were a project manager, an interpreter in a hospital and a communication manager in a company's export department.

\section{Concluding remarks}

This paper has presented a series of activities aimed at fostering entrepreneurial competence and thereby enhancing the employability of TI graduates. In the light of the teaching staff's perception of their progress and performance, the experience can be considered satisfactory.

Overall, this proposal can help students to 1) become aware of the versatility of TI and the range of professional profiles they can pursue, 2) learn to detect new market niches, taking full advantage of what they have to offer, and 3) acquire professional skills that will enhance their ability to perform successfully in the job market. Carrying out tasks that highlight a broad and interdisciplinary view of TI and contribute to identifying potential clients, such as beyond translation proper, the linguist as an activist or the personal route-map, fosters the acquisition of important areas of entrepreneurial competence (initiative and strategic vision, adaptability, self-confidence) and many sub-competences of TC. In addition, using active methodologies (class discussions, role-playing, proactive approaches), performing tasks directly related to the profession (the $\mathrm{CV}$ and cover letter, the professional website) and writing reasoned and reflective texts adjusted to the students' real situation and interests (the personal route-map) promote more meaningful learning.

It should be noted that the difficulties students experience when they have to promote themselves and create a demand for their services in potential clients are evidence that these skills, despite their importance for employability, are hardly addressed during the degree programme. The results of the exploratory study, which reveal how unaware students are of the potential of TI, also confirm the conclusions of other studies (Álvarez-Álvarez/Arnáiz-Uzquiza 2017, GalánMañas 2017) on the need for training in entrepreneurship. Apart from organising extracurricular seminars to deal with these aspects, a way to help compensate for this deficiency, given the transversality of the activities proposed, would be to use some of them in specialised translation course units or language courses. For example, in a medical translation course, students could create a wiki of professional aspects specifically related to the medical field, practise different professional tasks or even create a website offering their services and providing a sample of their translations. In doing so, the development of entrepreneurial competence could be somehow integrated into the curriculum, which would be useful when the requirements of the bachelor's degree in question did not allow the implementation of new course units for this purpose.

This study has certain limitations. On the one hand, regarding the exploratory study, the sample was small and the students were not from the same cohort. Therefore, a longitudinal study should be carried out to obtain a more reliable picture of the students' perceptions. On the other hand, the suitability of the activities proposed is based only on our own impressions as teachers. Thus, futu- 
re studies should aim to assess whether the activities actually contribute to acquire entrepreneurial competence. To do this, a second questionnaire could be distributed at the end of the course unit.

Finally, given that the inexorable automation of TI will force us to redefine the professional activities of translators and interpreters in the short to medium term, we consider that not working as a translator, in the purest and most traditional sense of the term, should not be interpreted by our graduates as a failure. They have the potential to perform activities that contribute to (improving) communication in a much broader sense. And our task is to continue exploring what they can contribute to society.

\section{References}

Álvarez-Álvarez, Susana/Arnáiz-Uzquiza, Verónica 2017: Translation and interpreting graduates under construction: do Spanish translation and interpreting studies curricula answer the challenges of employability? In The Interpreter and Translator Trainer 11:2-3, 139-59. doi: 10.1080/1750399X.2017.1344812.

Angelone, Erik 2018: Translator Training for New Intercultural Consulting Roles within the Language Industry. Paper presented at the $4^{\text {th }}$ International Conference on Research into Didactics of Translation (didTRAD: 20-22 June 2018). Barcelona: Universitat Autònoma de Barcelona.

Brøgger, Matilde N. 2017: When translation competence is not enough: A focus group study of medical translators. In Meta 62:2, 243-484.

Calvo, Elisa 2017: Servicios de valor añadido en contextos situacionales en Traducción: de los proyectos al portafolio. In Revista Digital de Investigación en Docencia Universitaria, 11:2, 136-154.

Calvo, Elisa/Kelly, Dorothy/Morón, Marián 2010: A project to boost and improve employability chances among Translation and Interpreting graduates in Spain. In Pellatt, Valerie/Giffiths, Kate/Wu, Shao-Chuan (eds.), Teaching and Testing Interpreting and Translating. Vol. 2. Berlin: Peter Lang, 209-226.

Castro, Xosé. El lingüista como activista. In El Trujamán, 26 September 2001 [online]. https://cvc.cervantes.es/trujaman/anteriores/septiembre_01/26092001.htm (accessed 10 December 2019).

Chouc, Fanny/Calvo, Elisa. Embedding employability in the curriculum and building bridges between academia and the workplace: a critical analysis of two approaches. In La linterna del traductor 4, 2010 [online] http://www.lalinternadeltraductor.org/n4/employability-curriculum.html (accessed 10 December 2019).

Dam, Helle V./Brøgger, Matilde N./Zethsen, Karen K. (eds.) 2018: Moving Boundaries in Translation Studies. Londres: Routledge.

Duarte Cueva, Franklin 2007: Emprendimiento, empresa y crecimiento empresarial. In Revista del Departamento Académico de Ciencias Administrativas 2:3, 46-56.

European Commission. Entrepreneurship in higher education, especially within non-business studies. Final Report of the Expert Group, 2008 [online]. https://ec.europa.eu/growth/content/final-report-expert-group-entrepreneurshiphigher-education-especially-within-non-business-0_en (accessed 10 December 2019).

European Ministers Responsible for Higher Education. Yerevan Communiqué, 2015. http://www.mab.hu/web/doc/kulfold/Yerevan_Communique.pdf. (accessed 10 December 2019).

Galán-Mañas, Anabel 2017: Programa para la mejora de la empleabilidad de los egresados en Traducción e Interpretación. Un estudio de caso. In Conexão Letras, 12:17, 153-171.

Galán-Mañas, Anabel 2018: Aprender a emprender en el grado de Traducción e Interpretación. In: Barceló, M. Tanagua/Velasco, Carmen (eds.), Evaluación, direccionalidad y orientación profesional en los estudios de Traducción e Interpretación. Málaga: EDA Libros, 33-55.

Galán-Mañas, Anabel/Hurtado Albir, Amparo 2015: Competence assessment procedures in translator training. In The Interpreter and Translator Trainer 9:1, 63-82.

González, Julia/Wagenaar, Robert 2003: Tuning Educational Structures in Europe. Final Report. Phase One. Bilbao: Universidad de Deusto.

González-Davies, María 2004: Multiple voices in the translation classroom: Activities, tasks and projects. Amsterdam: John Benjamins.

Henter, Sarah 2016: How Happy are Translators with their Studies? In Current Trends in Translation Teaching and Learning E 3, 24-66.

Hurtado Albir, Amparo 2007: Competence-based curriculum design for training translators. In The Interpreter and Translator Trainer, 1:2, 163-195. 
Jakobson, Roman 1959/2000: On linguistic aspects of translation. In: Venuti, Lawrence (ed.), The Translation Studies Reader. London: Routledge, 113-118.

Kelly, Dorothy 2002: Un modelo de competencia traductora: bases para el diseño curricular. In Puentes 1, 9-20.

Kelly, Dorothy 2007: Translator competence contextualized. Translator training in the framework of higher education reform: In search of alignment in curricular design. In Kenny, Dorothy/Ryou, Kyongjoo (eds.), Across Boundaries. International Perspectives on Translation Studies. Newcastle: Cambridge Scholars, 128-142.

Kiraly, Don 2016: Towards Authentic Experiential Learning in Translator Education. Göttingen: V\&R Academic Mainz University Press.

Marina, José Antonio 2010: La competencia de emprender. In Revista de Educación 351, 49-71.

Massey, Gary/Wieder, Regine 2018: Educating translators for new roles and responsibilities: Interfacing with corporate and technical communication. Paper presented at the $4^{\text {th }}$ International Conference on Research into Didactics of Translation (didTRAD: 20-22 June 2018. Barcelona). Barcelona: Universitat Autònoma de Barcelona.

Montalt, Vicent 2011: Hacia una visión perspectivista de la traducción. In Panace@, 12:33, 1-3.

Morón, Marián 2012: La figura del traductor-intérprete en procesos de internacionalización: el caso de las convocatorias de becas del ICEX. In Sendebar 23: 251-274.

Morón, Marián 2017: Del "texto" al "contexto" en la traducción comercial: bases de un modelo para la transversalidad de la traducción. In Sendebar 28, 95-112.

Morón, Marián/Medina, Ana 2016: La competencia del traductor que no "traduce": el traductor en ámbitos de internacionalización empresarial. In MonTI 8, 225-255.

Mossop, Brian 2016: "Intralingual translation": A desirable concept? In Across Languages and Cultures 17:1, 1-24.

Muñoz-Miquel, Ana 2016: Bridging the gap between professional practice and university training through socio-professional research: The case of medical translation. In Martín de León, Celia/González-Ruiz, Víctor (eds.), From the lab to the classroom and back again: Perspectives on translation and interpreting training. Frankfurt am Main: Peter Lang, 257-294.

Muñoz-Miquel, Ana 2018: Differences between linguists and subject-matter experts in the medical translation practice: An empirical descriptive study with professional translators. In Target 30:1,24-52.

Muñoz-Miquel, Ana/Montalt, Vicent/García-Izquierdo, Isabel 2017: La formación de posgrado en traducción médica: favorecer la empleabilidad mediante la versatilidad. Paper presented at the 8th International Conference of the Iberian Association of translation and Interpreting Studies (AIETI 8: 8-10 March 2017). Alcalá de Henares: Universidad de Alcalá de Henares.

PACTE 2003: Building a translation competence model. In Alves, Fabio (ed.), Triangulating Translation: Perspectives in Process Oriented Research. Amsterdam: John Benjamins, 43-66.

Pym, Anthony 2005: Training translators: Ten recurrent naiveties. In Translating Today 2, 3-6.

Rico, Celia/García, Álvaro. Análisis del sector de la traducción en España (2014-2015). Universidad Europea de Madrid, 2016 [online]. http://hdl.handle.net/11268/5057 (accessed 10 December 2019).

Rodríguez de Céspedes, Begoña 2017: Addressing employability and enterprise responsibilities in the translation curriculum. In The Interpreter and Translator Trainer 11:2-3, 107-122.

Thelen, Marcel 2016: The practice-oriented translator training curriculum: An example. Current Trends in Translation Teaching and Learning E 3, 163-200.

Torres-Simón, Ester/Pym, Anthony. European Masters in Translation. A comparative study [online]. http://usuaris. tinet.cat/apym/on-line/training/2016_EMT_masters.pdf (accessed 10 December 2019).

Toudic, Daniel (ed.). The Optimale employer survey and consultation, WP4 synthesis report, 2012 [online] http://www. translator-training.eu/attachments/article/52/WP4_Synthesis_report.pdf (accessed 12 April 2017).

Vandepitte, Sonia 2009: Entrepreneurial Competences in Translation Training. In Kemble, Ian (ed.), Proceedings of the conference The Changing Face of Translation. Portsmouth: University of Portsmouth.

Way, Catherine 2016: Intra-university projects as a solution to the simulated/authentic dilemma. In: Kiraly, Don (ed.), Towards authentic experiential learning in translator education. Gottingen: Mainz University Press, 147-160.

Working Group on Employability. Report to Ministers, Bologna Conference, Leuven/ Louvain-la Neuve 28-29 April 2009 [online] http://www.ond.vlaanderen.be/hogeronderwijs/bologna/conference/documents/2009_employability_ WG_report.pdf (accessed 15 May 2019).

Zethsen, Karen K. 2018: Access is not the same as understanding. Why intralingual translation is crucial in a world of information overload. In Across Languages and Cultures 19:1, 79-98. 


\section{APPENDIX 1}

FIRST-YEAR STUDENTS QUESTIONNAIRE

(Translated from Spanish)

The aim of this short survey is to know your opinion and expectations about the TI career. The survey is anonymous and should take no more than 5 minutes to complete. Please answer as honestly as possible. Thank you for your collaboration!

Did you know the degree well before enrolling on it?

For what reasons did you decide to study Translation and Interpreting?

What career opportunities do you think TI offers?

What professional tasks and activities do you think a graduate in TI can perform?

\section{FOURTH-YEAR STUDENTS QUESTIONNAIRE}

(Translated from Spanish)

The aim of this short survey is to know your opinion and expectations about the TI career, and compare them with those of first-year students. The survey is anonymous and should take only 5 minutes to complete. Please answer as honestly as possible. Thank you for your collaboration!

Did you know the degree well before enrolling on it?

For what reasons did you decide to study Translation and Interpreting?

Now that you are in your fourth year, what career opportunities do you think TI offers?

What professional tasks and activities do you think a graduate in TI can perform?

What would you like to do for a living? 